\title{
Flooding Vulnerability Assessment - A Case Study of Hou-Jing Stream in Taiwan
}

\author{
Meng-Ru Tsay \\ Department of Urban Planning, National Cheng Kung University, Tainan City 701, Taiwan \\ Mrtsay88@gmail.com \\ Han-Liang Lin \\ Department of Urban Planning, National Cheng Kung University, Tainan City 701, Taiwan
}

\section{Doi:10.5901/mjss.2013.v4n10p513}

\section{Abstract}

The research aims to determine how factors of population distribution, industry, and infrastructure influence the process of assessing flooding vulnerability. The main research goals are as follows:

1. To locate river basin inhabitants of sites vulnerable to flooding and define primary flood protection zones.

2. To evaluate the impact of flooding on industry.

3. To evaluate infrastructural sufficiency for handling floods.

The paper first summarizes related land-use and flood control measures for risk mitigation through literature review and a case study. The results of the case study provide a quantitative understanding of the effectiveness of practicing land use flood control measures based on concepts of flood risk management. The framework and simulation results of this paper provide a useful reference for urban planners who engage in risk assessment modeling.

Keywords: Vulnerability, Risk, Flooding

\section{Introduction}

Taiwan is situated in a location constantly vulnerable to typhoons attacks annually in summer and heavy rain in winter. It often rains densely and hard and due to the steep terrain, rivers flow quickly to the sea. While in urban areas, it causes flooding most of times. Flooding is the most frequently seen natural disasters in Taiwan.

In order to use ecological way to drain the water, we have adopted the concept of flood risk and land use planning. While the truth is that considerations of how to control flooding situations in a scale of a city is still lacking. The use of physiographic drainage-inundation model (PHD-mode) can simulate scenarios under various rainfall circumstances and helps to indicate appropriate flooding prevention strategies.

Recently, the setting of retention facility is based on Water Code and different levels of river, so as to enhance the ability to urban flooding prevention. In both typhoon Morakot(2009) and typhoon Fanapi(2011) severe damages and flooding along Hou-Jing Stream had been observed. In 2012, regulation project of flood-prone areas includes Hou-Jing basin area.

The research aims to determine how factors of population distribution, industry, and infrastructure influence the process of assessing flooding vulnerability. To simulate different flooding scenarios and implement adaptation strategies so as to plan and manage flood-prone areas.

\section{Literature Review}

\subsection{Physiographic Drainage-Inundation model, PHD-model}

In the past, we used to use PHD-model to simulate the flooding situations of typhoon Morakot and typhoon Fanapi which showed the high accurate ability are fit to real conditions and makes it reasonable to develop the model. There are a variety of land uses like farm lands, communities, parks, transportation systems and drainage systems and all of those land use can make a big difference in flows. In the process, we put a net to cover all over the research area and every 
grid of the net is considered as a cell. Each cell represents different geological status, and how the adjacent cells change water relies on water-flow continuity equation to describe.

\subsection{1 water-flow continuity equation}

There are three kinds of water exchange forms: river type links, weir type link, and culvert links. The interval between two adjacent cells is called river type links. When the interval between two adjacent cells is the roads, embankments and so on, it is called box culvert connection type. When the interval between two adjacent cells is separated by the road or box culvert, it is called culvert links.

\begin{tabular}{|c|c|c|}
\hline River type link & Weir type link & Culvert link \\
\hline & & \\
\hline
\end{tabular}

\subsubsection{Required input data of PHD-model}

A flooding simulation process requires enough input data for PHD-model and that includes three types of parameters: geometry data like no., area, coordinate and elevation; direction data like the number of adjacent cells, perimeter and water exchange form; feature data like manning the $\mathrm{N}$ value, infiltration rate, building coverage ratio.

\subsection{Disaster Risk Analysis}

In 1979, United Nations Disaster Relief Organization (UNDRO) defined definition of disaster risk in the report of natural disasters and vulnerability analysis (UNDRO, 1980): $\mathrm{R}($ Risk $)=\mathrm{H}$ (Hazard) $\times \mathrm{V}$ (Vulnerability)

Hazards mean human lives and property caused by damage, or a potential damage. American Risk and Insurance Association (ARIA) defined risks are consist of uncertainties, probability and loss. Whereas the risk is usually the results after the quantification, it is usually hard to gather complete data or proficiency calculation, to solve the problem we use risk matrix to indicate the level of disaster risk.

Table 1. Risk matrix

\begin{tabular}{|l|c|c|c|c|c|}
\hline \multirow{2}{*}{ Frequency } & \multicolumn{5}{|c|}{ Severity } \\
\cline { 2 - 6 } & severe (5) & serious (4) & medium (3) & Not serious (2) & None (1) \\
\hline Rare (1) & 6 & 5 & 4 & 3 & 2 \\
\hline seldom (2) & 7 & 6 & 5 & 4 & 3 \\
\hline sometimes (3) & 8 & 7 & 6 & 5 & 4 \\
\hline often (4) & 9 & 8 & 7 & 6 & 5 \\
\hline always (5) & 10 & 9 & 8 & 7 & 6 \\
\hline
\end{tabular}

Disaster risk analysis is mainly the estimation of disasters degree and distribution characteristics to analyze some areas disaster's influence and impact. It contains identification of risk factor, hazard analysis, vulnerability analysis and estimates level of risk.

\subsection{Land Use and Coping Strategies}

Flood simulation mechanism can identify three types of coping strategies. First, there are needs of flood control facilities to minimize the loss of damage in developed areas in between high developed density area where it is near the river at the same time. Second, low cost engineering ways are talking about regional scaled areas and developing cases. 
Designating protection areas for planting trees and constructing retention facilities are common solutions. Last, we plan land use planning such as regional planning and ecological planning to distinguish risk areas by the degree of risk.

\section{Method}

\subsection{Research Scope}

The research aims to determine how factors of population distribution, industry, and infrastructure influence the process of assessing flooding vulnerability, simulate flooding situations under different rainfall scenarios and finally implement land use and coping strategies for planning flood-prone areas.

\subsection{Data Collection}

\subsubsection{Geographical environment}

The empirical area of the research is Hou-Jing basin area. Its area is approximately 73.45 square kilometers. The HouJing drainage system which is also an important river consists of Nan Zi drainage system. Shilong River drainage system and Tsao-Kung irrigation system.

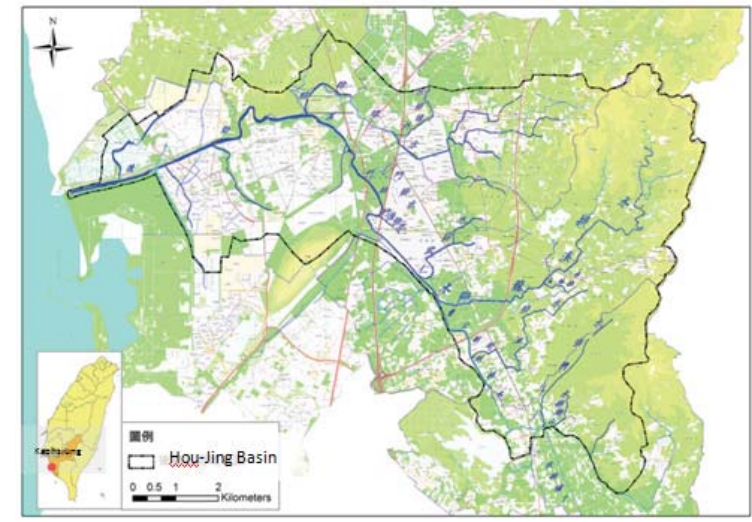

Figure 1. Main rivers distribution in Hou-Jing basin

\subsubsection{Historical disasters}

Hou-Jing drainage system is still under construction so it cannot functionally drain water when it comes heavy rain fall or a typhoon. After we had a site visiting and diagnosed the main reasons are followings: drainage paths are flat and hard to lead the water to go, dusts and stones come with water stay at the tunnels, and broken drainage system managements.

\section{Methodology section}

Followings are the research process: To collect land use survey information in 1995, to develop flooding simulation procedures, to classify the hazard factors, to categorize the vulnerable factors, to calculate the risk factor and finally get the risk map done.

\subsection{Hazard Map}

The research uses PHD-model as a main research tool. We gathered the rainfall information from the meteorological weather station at Zuzijio and its annual maximum series over 24 hours. The tide data is at the Kaohsiung port station. In order to simulate more cases in severe flooding places, we used mean water level $0.9 \mathrm{~m}$ as the parameter. The analysis 
of the peak flow is triangular unit, rainfall intensity formulas and coordinate system is TWD 97. Recurrence interval is based on water code which it said river managed by county should build embankment for 10 years rainfall return period and 10 year return period time of flooding hazard map. The most important parameter on the flooding hazard map in the empirical area of Hou-Jing area is water depth (WD). Finally, we divided the WD into 5 levels: 0-0.3m, 0.3-0.5m, 0.5$1.0 \mathrm{~m}, 1.0-3.0 \mathrm{~m}$, and $3.0 \mathrm{~m}$ and more. In the research, we have both 10 year return period flooding hazard map and 25 year return period flooding hazard map.

Table 2. 10-year return period flood depth chart, 25-year return period flood depth map

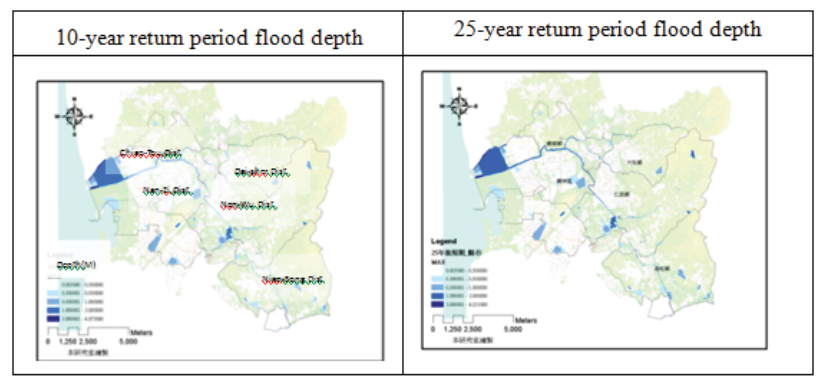

\subsection{Vulnerability map}

\begin{tabular}{|l|l|}
\hline & \multicolumn{1}{|c|}{ Factor } \\
\hline Population & Population, the number of elderly living alone, residential land use \\
\hline Industry & $\begin{array}{l}\text { Farming: farm land, animal husbandry, agriculture incidental } \\
\text { facilities; aquaculture; business; industrial }\end{array}$ \\
\hline Facility & Organizations, schools, health care, leisure facilities \\
\hline
\end{tabular}

\subsection{Risk Map}

\subsubsection{Population Risk Map}

In the research, we assume that the flood vulnerability analysis in the Hou-Jing area is the same. Population vulnerability consists of population density and numbers of elderly. Population density is a measurement of population living in the village in Hou-Jing area.

Vulnerability $_{\curlywedge 口}=\mathrm{V}($ ai,, $\mathrm{i})$

ai : Population density, where the population is allocated to each of the years in building

$\beta i$ : Anyang institutionalized elderly persons

After completing constructing database, we put data into the geographic information system for population calculation and made some grading and overlay operations to get vulnerability maps. We divided population density ai into five levels and used the same color but deep to shallow to represent its level and give grades from 1 to 5 to represent its level as well. As for weight part, elders represent grades of 5 . Finally, we can have a simple matrix of 5 levels: lowest (1 to 2), low (3-4), medium (5-6), high (7-8) and highest (9 to 10).

Risk population $=$ Hazard ${ }^{\star}$ Vulnerability population

Table 3. The exposure and vulnerability weighted degree classification

\begin{tabular}{|c|c|c|c|c|c|}
\hline Exposure vulnerability & 1 & 2 & 3 & 5. & 5 \\
\hline 0 & 1lowest & 2lowest & 3low & 5 low & 5 low \\
\hline 5 & 6 medium & 7high & 8high & 9 highest & 10 highest \\
\hline
\end{tabular}




\subsubsection{Industry Risk Map}

Different industries have different types of vulnerability. Because vulnerability is composed of three components: exposure, resilience, resistance to damage intensity. Exposure factor is based on flooding area and break into 5 levels. Resilience is according to differences of land uses from Industrial areas, commercial areas, aquaculture areas and farm lands and the bearable WD is $10 \mathrm{~cm}, 10 \mathrm{~cm}, 30 \mathrm{~cm}, 50 \mathrm{~cm}$. Finally, we can have a simple matrix of 3 levels: lowest (2 to 3), low (4), medium (5), high (6-7) and highest (8).

Table 4. The exposure and vulnerability weighted degree classification

\begin{tabular}{|c|c|c|c|c|c|}
\hline $\begin{array}{c}\text { exposure } \\
\text { vulnerability }\end{array}$ & 1 & 2 & 3 & 5. & 5 \\
\hline 1 & 2 lowest & 3 lowest & 4 low & 6 high & 6 high \\
\hline 2 & 3 lowest & 4 low & 5 medium & 6 high & 7 high \\
\hline 3 & 4 low & 5 medium & 6 high & 7 high & 8highest \\
\hline
\end{tabular}

Vulnerability Industrial= V(ai, $\beta \mathrm{i}, \gamma \mathrm{\gamma i}, \mathrm{\delta i})$

ai : Farm land area

ßi : Aquaculture area

yi : Commercial area

סi : Industrial area

Risk Industrial $=$ Hazard *Vulnerability Industrial

C. Facilities risk maps

Vulnerability of facilities can be categorized into schools, health care, leisure facilities. And its exposure to flooding in ascending order by size divided into five levels, lowest (1), low (2), medium(3), high (4) and highest (5).

Vulnerability Facility $=a i+\beta i+\gamma i$

ai:Organization area

ßi:School area

үi:Health care area

Risk Facility $=$ Hazard *Vulnerability Facility

\section{Conclusions and Policy Suggestion}

Risk map is the combination of flooding hazard and vulnerability, and most of time governments take it as a risk assessment and damage prevention index. After completing hazard map and vulnerability map then we can make risk map. The risk matrix combined with two factors of hazard and vulnerability, and we distributed different values of risk in village scaled map. The goal is to compare high risk map to the current use and urban planning to figure out places with impropriate developments so as to bring out regional planning and urban design.

\subsection{Population risk maps:}

Comparing population vulnerability map to flooding hazard map, we can find out that high risk area are mostly in Renwu district, Nanzi district and Niaosong district. Also, there is high risk area distributing in Zaoying district. In this area, it is one of the earliest developed areas among Kaohsiung so the main land use is residential areas. Where it is situated is near Love river so it usually affected by typhoon season and heavy rainfall. However, there is important transportation systems Zaoying district and that attracts many people to move into this area. It is necessary to construct retention facility, water drainage system and so on. 


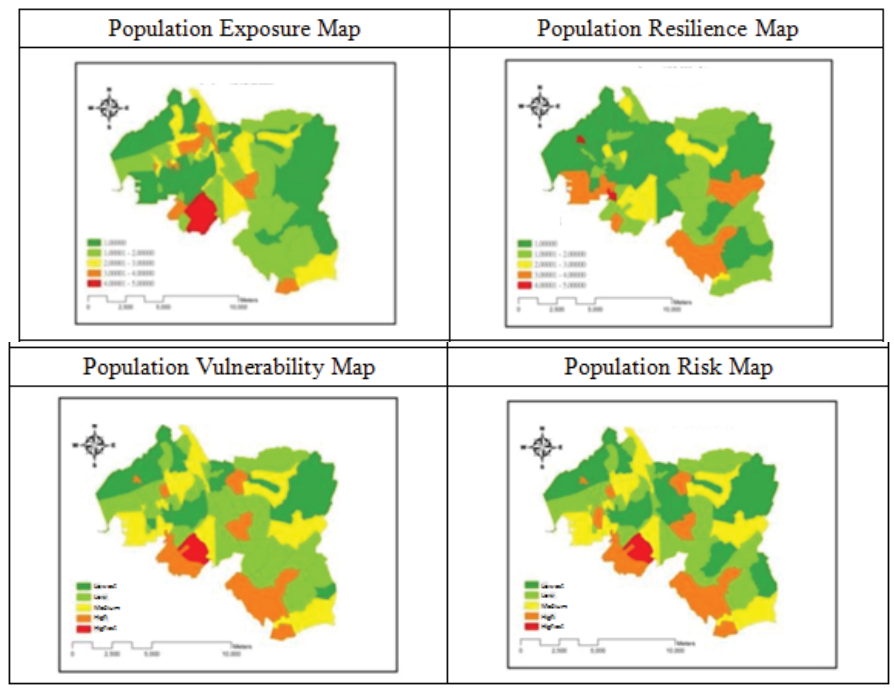

\subsection{Industry risk maps and facility risk maps}

First, comparing industry vulnerability map to flooding hazard map, we can find out that high risk area are mostly in Renwu district, Niaosong district, and Fongshang district. Second, comparing facility vulnerability map to flooding hazard map, we can find out that high risk area are mostly in Nanzi district and Zaoying district. Both industry risk map and facility risk map indicate that high risk areas locate in Nanzi district and Renwu district. In Nanzi district, there are plenty public facilities like Kaohsiung Metropolitan Park, New Town Development, sewage treatment plants and many other facilities are still under construction. While in Renwu district, according to urban planning in this area, it needs flooding prevention construction plan. As for low height place or not smoothed water drainage places, it is keen to make the building lots higher so as not to let water flow goes in.

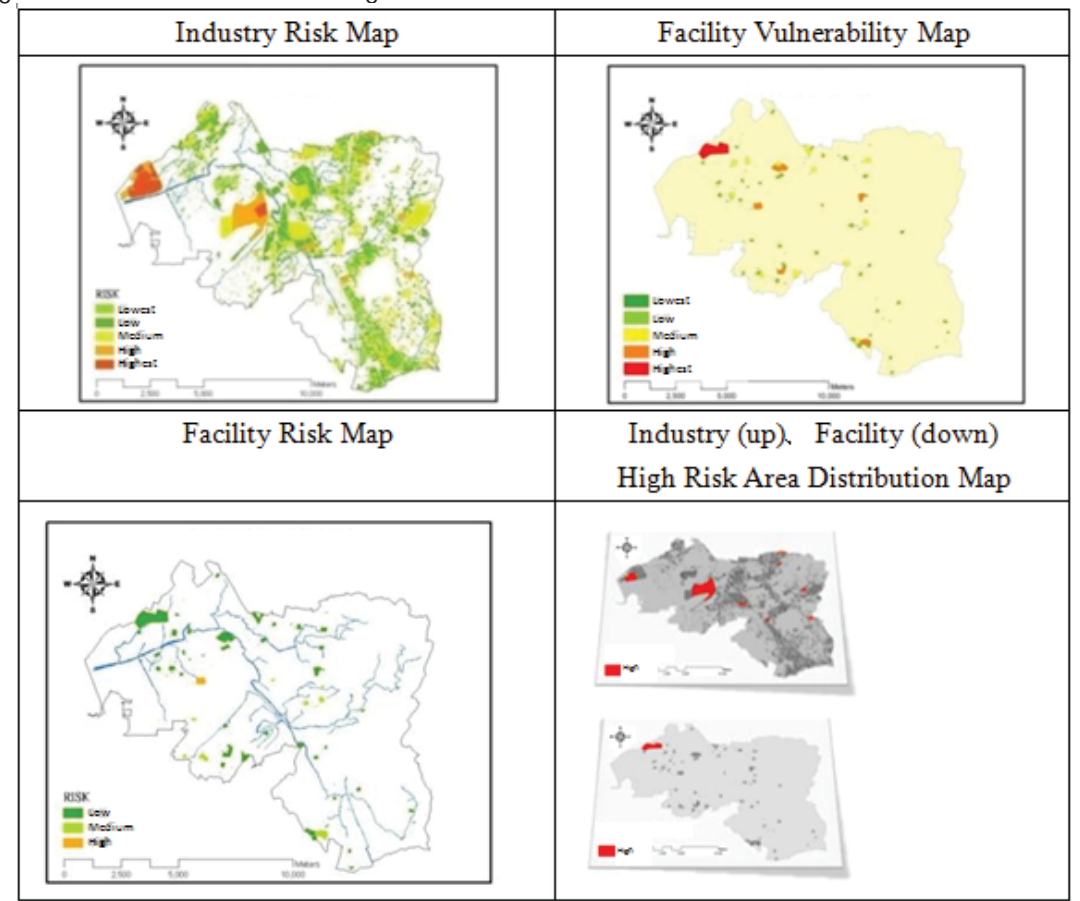




\section{Acknowledgement}

This research was one part of Study "Master Plan of Management of Hou-Jing River Basin/ Urban and Rural Landscape Improvement Plan. I would be thankful to National Science Council for financial I support. The funds were used to employ students in survey design, questionnaire survey, data collection, data analysis and the writing of this research program.

\section{References}

Bucheli, B. (2006). Flood-risk mapping: contributions towards an enhanced assessment of extreme events and associated risks

Tsai, C. T. (2007). A study on the development the physiographic inundation warning model for the drainage system in the coastal lowaltitude plains

Liao, H. H., (2009). A Study of the Inundate-Drain Model of Streets-Sewers in Urban District

Tsao, C. W. (2009). A Study of Basin Storm-Flood Computational Model

Huang, Y. S. (2009). The Establishment of Vulnerability Evaluation Indexes: The Case of Shueili Township, Nantou, Taiwan

Lin, H. L. (2010). The approach to assess suitable lands for migration around disaster-prone areas

Chen, W. L. (2010). Assessing Land Use Flood Control Measures Based on Flood Risk Management Approach--A Case of Yanshuei River Basin, Taiwan

Tung, C. P. (2011). Investigation on Analysis Method of Flood Vulnerability and Risk Maps

Risk Management Solution, (2002). Central Europe Floods Whitepaper

United Nations, (2002). Guidelines for Reducing Flood Losses

APFM, (2004). "Integrated Flood Management-Concept Paper" The Associated Programme on Flood Management

APFM, (2004). Manual for Community-based Flood Management in Bangladesh

United Nations, (2007). International Flood Initiative

United Nations, (2007). International Strategy for Disaster Reduction Reducing risks of disaster posed by climate change

RIBA, (2009). Climate Change Toolkit Designing for flood Risk

ISDR, (2011). Stop Disasters (Flooding Fact)

Water Resources Agency, (2011). A Demonstration Project for Producing Maps of Vulnerability and Risk in the Gaoping River, Donggang River, Kaohsiung City and County, and Pingtung County.

Water code, (2011).

UNISDR, (2012). Floods becoming more dangerous, more costly, says World Bank

International Strategy for Disaster Reduction, Terminology: Basic terms of disaster risk reduction http://www.unisdr.org/

World Climate Programme (WCP) http://www.wmo.int/pages/prog/wcp/index_en.html

National Science and Technology Center for Disaster Reduction, NCDR http://ncdr.nat.gov.tw/ 